\title{
Protein Tyrosine Phosphatase Receptor Type 0 Inhibits Trigeminal Axon Growth and Branching by Repressing TrkB and Ret Signaling
}

\author{
Graziana Gatto, ${ }^{1}$ Irina Dudanova, ${ }^{1}$ Philipp Suetterlin, ${ }^{2}$ Alun M. Davies, ${ }^{3}$ Uwe Drescher, ${ }^{2}$ John L. Bixby, ${ }^{4}$ \\ and Rüdiger Klein ${ }^{1}$ \\ ${ }^{1}$ Department of Molecules-Signaling-Development, Max Planck Institute of Neurobiology, D-82152, Martinsried, Germany, ${ }^{2}$ Medical Research Council \\ Centre for Developmental Neurobiology, King's College London, SE1 1UL, London, United Kingdom, ${ }^{3}$ School of Biosciences, CF10 3AT, Cardiff, United \\ Kingdom, and ${ }^{4}$ Miami Project to Cure Paralysis, University of Miami Miller School of Medicine, Miami, Florida 33136
}

Axonal branches of the trigeminal ganglion (TG) display characteristic growth and arborization patterns during development. Subsets of TG neurons express different receptors for growth factors, but these are unlikely to explain the unique patterns of axonal arborizations. Intrinsic modulators may restrict or enhance cellular responses to specific ligands and thereby contribute to the development of axon growth patterns. Protein tyrosine phosphatase receptor type 0 (PTPRO), which is required for Eph receptor-dependent retinotectal development in chick and for development of subsets of trunk sensory neurons in mouse, may be such an intrinsic modulator of TG neuron development. PTPRO is expressed mainly in TrkB-expressing $\left(\mathrm{TrkB}^{+}\right)$and $\mathrm{Ret}^{+}$mechanoreceptors within the TG during embryogenesis. In PTPRO mutant mice, subsets of TG neurons grow longer and more elaborate axonal branches. Cultured $P T P R O^{-1-} \mathrm{TG}^{-}$ neurons display enhanced axonal outgrowth and branching in response to BDNF and GDNF compared with control neurons, indicating that PTPRO negatively controls the activity of BDNF/TrkB and GDNF/Ret signaling. Mouse PTPRO fails to regulate Eph signaling in retinocollicular development and in hindlimb motor axon guidance, suggesting that chick and mouse PTPRO have different substrate specificities. PTPRO has evolved to fine tune growth factor signaling in a cell-type-specific manner and to thereby increase the diversity of signaling output of a limited number of receptor tyrosine kinases to control the branch morphology of developing sensory neurons. The regulation of Eph receptor-mediated developmental processes by protein tyrosine phosphatases has diverged between chick and mouse.

\section{Introduction}

The trigeminal ganglion (TG) topographically innervates distinct facial regions through its three main branches (maxillary, mandibular, and ophthalmic) and conveys mainly sensations of pain, touch, and temperature (Erzurumlu et al., 2010). Work over the past decades has identified periphery-derived signals, such as members of the nerve growth factor (NGF), glial cell line-derived neurotrophic factor (GDNF), semaphorin, and slit families, all having some degree of growth-promoting and branching activities or guidance function (Davies, 1997; Rochlin et al., 2000;

Received Oct. 4, 2012; revised Jan. 17, 2013; accepted Feb. 12, 2013.

Author contributions: G.G., A.M.D., U.D., and R.K. designed research; G.G., I.D., and P.S. performed research; J.L.B. contributed unpublished reagents/analytic tools; G.G., I.D., P.S., and U.D. analyzed data; G.G., J.L.B., and R.K. wrote the paper.

This study was supported by the Max Planck Society, the European Union [MOLPARK (Molecular mechanisms of neuronal restoration: novel approaches for Parkinson's disease)], the German Research Foundation (Collaborative Research (entre 870), the National Institutes of Health, and the Wellcome Trust. We thank L. Gaitanos for technical assistance, D. Marinescu and S. Krinner for mouse genotyping, A. Huber-Brösamle, T. Matozaki, and Eek-hoon Jho for kindly providing reagents, and T. Gaitanos, P. Klein, and S. Paixão for fruitful discussions.

The authors declare no competing financial interests.

Correspondence should be addressed to Rüdiger Klein, Department of Molecules-Signaling-Development, Max Planck Institute of Neurobiology, Am Klopferspitz 18A, D-82152, Martinsried, Germany. E-mail: rklein@neuro.mpg.de.

DOI:10.1523/JNEUROSCI.4707-12.2013

Copyright $\odot 2013$ the authors $\quad 0270-6474 / 13 / 335399-12 \$ 15.00 / 0$
Airaksinen and Saarma, 2002; Ma and Tessier-Lavigne, 2007). However, our understanding of the development of branched neuronal morphologies is still poor. Subsets of TG neurons express different receptors for neurotrophic factors, but these factors alone cannot explain the many unique axonal arborization patterns. Receptor-associated proteins, such as members of leucine-rich repeat (LRR) and Ig superfamilies, enhance or suppress receptor activities to control sensory axon growth, guidance, or branching (Ledda et al., 2008; Mandai et al., 2009). It is possible that other intrinsic modulators of neurotrophic factor receptors contribute to the development of stereotyped axon growth patterns.

The receptor-type protein tyrosine phosphatase (RPTP) PTPRO (protein tyrosine phosphatase receptor type O), a member of the R3 subfamily (Matozaki et al., 2010), has been implicated previously in motor and retinal ganglion cell (RGC) axon guidance in the chick (Stepanek et al., 2001, 2005; Shintani et al., 2006). In mouse, PTPRO was shown to be required for survival and correct axonal projection of trunk sensory neurons (Gonzalez-Brito and Bixby, 2009). PTPRO has not been implicated previously in trigeminal sensory neuron development, and the tyrosine-phosphorylated substrates of PTPRO in the mouse remained uncharacterized. 
PTPRO can dephosphorylate TrkC, the receptor for neurotrophin-3 (NT-3) (Hower et al., 2009), and all members of the neurotrophin family-NGF, brain-derived neurotrophic factor (BDNF), NT-3, and NT-4-regulate various aspects of trigeminal neuron development, including cell survival, axon growth, branching, and guidance (Reichardt, 2006). Hence, Trk receptors were prime substrate candidates of PTPRO. PTPRO may also regulate Ret receptor signaling by GDNF family ligands, which are required for development of subsets of dorsal root ganglia (DRG) (Luo et al., 2007, 2009,) and trigeminal neurons (Airaksinen and Saarma, 2002). Finally, Eph receptor tyrosine kinases (RTKs) have been identified previously as PTPRO substrates in the chick retinotectal system (Shintani et al., 2006). One member of this large receptor family, EphA4, is required for sensory innervation of vibrissae in mice (North et al., 2010), suggesting that mouse PTPRO (mPTPRO) may modulate Eph signaling in TG neurons.

Here, we describe novel functions for PTPRO as a regulator of neurotrophin receptor signaling in trigeminal axon arborization and growth during mouse embryogenesis. Genetic ablation of PTPRO expression in mice enhanced the outgrowth of trigeminal neurons, resulting in an increased arbor size and complexity of the ophthalmic nerve in vivo and in an enhanced response to BDNF and GDNF ex vivo. Moreover, ablation of PTPRO did not change the sensitivity of trigeminal, RGC, or motor axons to ephrins, suggesting that the regulation of Eph receptors during development by RPTPs has diverged between chick and mouse.

\section{Materials and Methods}

Mice. PTPRO ${ }^{-1-}$ and Hb9-GFP transgenic mice have been described previously (Wharram et al., 2000; Wichterle et al., 2002). All the mutants were maintained in a comparable mixed 129/P3J $\times$ C57BL/6 background. Embryos used were of either sex.

Immunostaining. Embryonic day 10.5 (E10.5), E11.5, E12.5, and E15.5 embryos and newborn pups were fixed in $4 \%$ paraformaldehyde (PFA) for $2 \mathrm{~h}$ or overnight and then incubated overnight in 30\% sucrose. Cryostat sections of $30 \mu \mathrm{m}$ were blocked in $4 \%$ goat serum, $4 \%$ donkey serum, $2 \%$ bovine serum albumin (BSA), and $0.3 \%$ Triton X-100 in PBS. Primary antibodies were applied overnight in $4 \%$ goat serum, $4 \%$ donkey serum, $2 \% \mathrm{BSA}$, and $0.1 \%$ Triton $\mathrm{X}-100$ at $4^{\circ} \mathrm{C}$. After 45 min washes in PBS, sections were incubated with secondary antibodies (1:200) at room temperature for $1 \mathrm{~h}$. After $45 \mathrm{~min}$ in PBS, cryosections were mounted using Dako fluorescent medium. The following primary antibodies were used: rat anti-PTPRO (1:200; kindly provided by Prof. Takashi Matozaki, Gunma University, Maebashi, Gunma, Japan), rabbit anti-Lim1 (1:1000; kindly provided by Dr. Andrea Huber, German Research Center for Environmental Health, Neuherberg, Germany), mouse anti-Islet1 (1:50; Developmental Studies Hybridoma Bank), rabbit anti-TrkA (1:500; Millipore), goat anti-TrkB (1:500; R\&D Systems), goat anti-TrkC (1:500; $\mathrm{R} \& D$ Systems), goat anti-Ret (1:100; R\&D Systems), mouse anti-NeuN (1:500; Millipore), and mouse anti-Tuj1 (1:100; Covance). Images were acquired at the Axioplan epifluorescent microscope (Carl Zeiss). For analysis of colocalization and to count neurons, images were acquired using the confocal microscope (Spinning Carl Zeiss Axio Observer Z1 with a Yokagawa Spinning Disk Confocal Unit and a Cool SNAP HQ ${ }^{2}$ CCD Camera).

Neurofilament staining on the whole embryo. E11.5 and E12.5 embryos were fixed overnight in Dent's solution (1 part DMSO, 4 parts methanol). Then, they were bleached in one part $30 \% \mathrm{H}_{2} \mathrm{O}_{2}$ and two parts Dent's solution for several hours at room temperature. Three washing steps ( $1 \mathrm{~h}$ each at room temperature) in PBS containing $0.2 \%$ gelatin and 1\% Triton X-100 (Sigma) were followed by incubation with the antineurofilament antibody (1:300 in 4 parts newborn calf serum, 1 part DMSO; NF-160; Sigma) overnight at room temperature. Five washing steps in TBS containing $1 \%$ Triton X-100 and $0.2 \%$ gelatin for $1 \mathrm{~h}$ each were followed by incubation with anti-mouse horseradish peroxidase
(HRP)-conjugated antibody (1:300 in 4 parts newborn calf serum, 1 part DMSO) overnight at room temperature. Finally, embryos were washed and developed in diaminobenzidine working solution followed by dehydration in methanol and clearing in BABB (1 part benzyl alcohol, 2 parts benzyl benzoate). Images were acquired using the DC150 camera from Leica and analyzed using NIH ImageJ or NeuronJ. The ophthalmic nerve phenotype at E11.5 was quantified as the ratio between the area of the ophthalmic nerve arbor and the area of the maxillary nerve arbor. The ophthalmic nerve arbor complexity at E12.5 was analyzed using the Sholl analysis plug-in of NeuronJ. The hindlimb phenotype at E12.5 was quantified as the ratio between the diameter of the tibial nerve and the diameter of the peroneal nerve.

Trigeminal neuron cultures. Dissociated cultures of trigeminal neurons from E12.5 embryos were grown onto polyornithine/laminin-coated four-well plates. Neurons were grown for $18 \mathrm{~h}$ in F-12 medium supplemented with $10 \mathrm{ng} / \mathrm{ml} \mathrm{NGF}$ (R\&D Systems), and when indicated, $5 \mathrm{ng} / \mathrm{ml}$ BDNF (R\&D Systems) or $5 \mathrm{ng} / \mathrm{ml}$ GDNF (R\&D Systems) were added to the culture medium. Neurons were fluorescently labeled with calcein-AM (Invitrogen) and imaged with an Axiovert 200M microscope (Carl Zeiss) using a $10 \times$ objective. Neurite length and number of branches were estimated as described previously (Gutierrez and Davies, 2007). For the culture in the presence of caspase inhibitors, neurons were grown onto polyornithine/laminin-coated coverslips for $18 \mathrm{~h}$ in F-12 medium supplemented with $10 \mu \mathrm{M}$ Q-VD-Oph (Calbiochem) and NGF, BDNF, or GDNF as indicated. Neurons were stained with cell tracker green (Invitrogen) and fixed 5 min with 4\% PFA, and coverslips were mounted using Dako fluorescent medium. Images were acquired with Carl Zeiss epifluorescent microscope. Explant cultures of trigeminal neurons from E12.5 embryos were grown on poly-D-lysine/laminin-coated coverslips for $15 \mathrm{~h}$ in F-12 medium supplemented with $10 \mathrm{ng} / \mathrm{ml} \mathrm{NGF}$.

Motor neuron cultures. Explant cultures of motor neurons from the lower half of E12.5 lumbar lateral motor column (LMC) were grown on poly-D-lysine/laminin-coated coverslip. Neurons were grown for $15 \mathrm{~h}$ in Neurobasal medium supplemented with B27, glutamine, glutamate, penicillin/streptomycin, $1 \mathrm{ng} / \mathrm{ml} \mathrm{BDNF}, 1 \mathrm{ng} / \mathrm{ml} \mathrm{GDNF}$, and $10 \mathrm{ng} / \mathrm{ml}$ ciliary neurotrophic factor.

Growth cone collapse assay. Trigeminal explants were stimulated for 30 min with $0.5 \mu \mathrm{g} / \mathrm{ml}$ preclustered ephrinA5 or with $0.5 \mu \mathrm{g} / \mathrm{ml}$ preclustered human IgG Fc fragments as a control. Motor neuron explants were stimulated for $30 \mathrm{~min}$ with 0.1 and $0.5 \mu \mathrm{g} / \mathrm{ml}$ preclustered ephrinA2/A5 (mixed 1:1) or with 0.1 and $0.5 \mu \mathrm{g} / \mathrm{ml}$ preclustered human IgG Fc fragments as a control. Explants were fixed twice for $30 \mathrm{~min}$ in 2\% PFA-15\% sucrose, blocked in $0.5 \%$ Triton X-100, $1 \%$ BSA in PBS, and then stained using Phalloidin-568 (1:100; Invitrogen). Coverslips were mounted using Dako fluorescent medium, and images were acquired with an Axioplan epifluorescence microscope (Carl Zeiss).

Cell culture and Western blot. HEK293 and HeLa cells were cultured in DMEM supplemented with $10 \%$ fetal bovine serum and $1 \%$ penicillin/ streptomycin. Cells were transfected using Lipofectamine2000 (Invitrogen), according to the instructions of the manufacturer, kept at $37^{\circ} \mathrm{C}$ for $24 \mathrm{~h}$, then stimulated with $50 \mathrm{ng} / \mathrm{ml} \mathrm{BDNF}$ or $50 \mathrm{ng} / \mathrm{ml} \mathrm{GDNF}$ and soluble GFR $\alpha 1$ (R\&D Systems), and harvested. Plasmids for mammalian expression used were mPTPRO in pFlag-CMV-5 (kindly provided by Dr. Eek-hoon Jho, The University of Seoul, Seoul, Republic of Korea), cPTPRO-Flag in pcDNA3, TrkB in pMEX-neo, EphA4 in pFlagCMV-3, and Ret51 in pcDNA3. Lysis buffer (50 mm Tris-HCl, pH 7.5, $150 \mathrm{~mm} \mathrm{NaCl}$, and $1 \%$ Triton X-100) was supplemented with protease inhibitor cocktail and phosphatase inhibitor cocktail tablets (Roche). Proteins were separated by $7.5 \%$ SDS-PAGE, transferred onto nitrocellulose membranes and blotted with the following primary antibodies: rabbit anti-Flag (1:1000; Sigma), goat anti-TrkB (1:1000; R\&D Systems), mouse anti-phosphotyrosine (1:1000; hybridoma clone 4G10), mouse anti-phospho-p44/42 MAPK (1:2000; Cell Signaling Technology), rabbit anti-p44/42 MAPK (1:1000; Cell Signaling Technology), mouse antiphospho-Ret pY1062 (1:1000; R\&D Systems), goat anti-Ret (1:1000; Fitzgerald), rabbit anti-phospho-Eph (1:1000; Abcam), and mouse antiEphA4 (1:5000; Zymed). The blots were then incubated with HRPconjugated secondary antibodies (1:5000; GE Healthcare). Luminol (GE Healthcare) was used for chemiluminescence detection. For immuno- 
precipitations, lysates were incubated overnight at $4^{\circ} \mathrm{C}$ with $\operatorname{TrkB}$ antibody (R\&D Systems). The protein A-Sepharose beads (GE Healthcare) were then added to the mixture and incubated at $4^{\circ} \mathrm{C}$ for $2 \mathrm{~h}$.

Cell culture immunostaining. Transfected HeLa cells were stimulated with $50 \mathrm{ng} / \mathrm{ml} \mathrm{BDNF}$ or GDNF/GFR $\alpha 1$ and fixed in 4\% PFA for $20 \mathrm{~min}$ on ice. Then they were permeabilized in $0.1 \%$ Triton X-100 in PBS, blocked in 3\% BSA in PBS, and stained with rabbit anti-Flag (1:1000; Sigma) to detect PTPRO expression, rat anti-PTPRO (1:200) to detect PTPRO surface expression, goat anti-TrkB (1:500; R\&D Systems), goat anti-Ret (1:200; R\&D Systems), and mouse anti-phosphotyrosine (1:500; 4G10; Millipore), and with Cell Mask Blue (1:1000; Invitrogen) to detect the cell outline. To determine the surface expression of TrkB, Ret and PTPRO cells were not permeabilized. A single plane of a confocal stack was analyzed using NIH ImageJ plugin to determine the colocalization of TrkB and Ret with PTPRO before and after stimulation. Using MetaMorph, the outline of the cells was drawn based on the Cell Mask Blue staining, and the intensity was determined for TrkB, Ret, and the phosphotyrosine stainings.

Retrograde tracings. E12.5 embryos were eviscerated and kept in DMEM/F- 12 medium (Invitrogen) aerated with 5\% $\mathrm{CO}_{2} / 95 \% \mathrm{O}_{2}$. A $6 \%$ lysine-fixable tetramethylrhodamine-dextran (molecular weight of 3000; Invitrogen) solution in PBS with $0.4 \%$ Triton X-100 was injected into the ventral hindlimb and allowed to diffuse for 5-6 h at room temperature.

Anterograde tracings. Anterograde tracing experiments were essentially performed as described by Rashid et al. (2005). In brief, the offspring from crosses of $P T P R O^{+/-}$mice was analyzed at postnatal day 8 (P8), a time at which the retino-collicular projection is considered mature. Anterograde tracing of RGC axons was performed by focal injection of DiI (Invitrogen) as a 10\% solution in dimethylformamide into the peripheral region of the nasal retina. Approximately $24 \mathrm{~h}$ later, mice were deeply anesthetized and perfused transcardially with PBS. The superior colliculus and inferior colliculus as well as the injected retinae were whole mounted onto glass slides and examined under UV light. The injection sites of all retinae were verified by fluorescence imaging of flat mounts.

\section{Results}

\section{PTPRO is expressed in developing TrkB-expressing and Ret-expressing trigeminal neurons}

To understand the role of PTPRO in developing TG neurons, we examined its temporal expression pattern by immunostaining between E10.5 and P0. The specificity of the PTPRO antibody was tested on different tissues from PTPRO wild-type and $P_{T P R O}^{-1-}$ embryos (data not shown; see also Kotani et al., 2010). At E10.5, PTPRO is barely detectable in trigeminal neurons, but by E11.5, PTPRO expression is seen on trigeminal cell bodies and axons. PTPRO expression is maintained through all later stages of embryonic development and in newborns (Fig. $1 A-F)$. TG neurons are subdivided into several subpopulations, including TrkA-expressing $\left(\operatorname{TrkA}^{+}\right)$nociceptive, $\operatorname{TrkB}{ }^{+}$ or Ret ${ }^{+}$mechanoceptive, and $\operatorname{TrkC}^{+}$neurons. Later in development, TrkA ${ }^{+}$neurons further differentiate into peptidergic and non-peptidergic neurons and start expressing Ret (Marmigère and Ernfors, 2007). To investigate which subpopulations expressed PTPRO, we performed coimmunostainings with TrkA, TrkB, TrkC, and Ret antibodies at three different developmental stages: E12.5 (axon elongation and branching), E15.5 (axon arborization), and P0 (Erzurumlu et al., 2006). At E12.5, PTPRO was expressed in approximately half of $\mathrm{TrkB}^{+}$and $\operatorname{Ret}^{+}$, in a small population of $\operatorname{TrkC}^{+}$, but rarely in $\mathrm{TrkA}^{+}$neurons (Fig. $1 C-F)$. At E15.5, and similarly at P0, PTPRO expression strongly decreased in $\mathrm{TrkB}^{+}$but remained high in $\mathrm{Ret}^{+}$neurons, and did not increase in the other two populations (Fig. $1 B-F$ and data not shown). The expression pattern suggested that PTPRO was localized in mechanoceptive trigeminal neurons in the early phases of development. Because PTPRO is reportedly expressed in E16.5 DRGs (Beltran et al., 2003), we also performed immunostainings in developing lumbar DRGs. At E12.5 and E15.5, PTPRO was expressed primarily in $\mathrm{TrkB}^{+}$and $\operatorname{Ret}^{+}$neurons, as observed for the TG. By birth, expression decreased in $\mathrm{TrkB}^{+}$and Ret ${ }^{+}$and increased in $\mathrm{TrkC}^{+}$neurons. PTPRO expression in TrkA ${ }^{+}$neurons was low across stages (data not shown).

\section{$\mathrm{PTPRO}^{-/-}$embryos show increased complexity of the ophthalmic branch and defasciculation of the maxillary branch}

To test whether PTPRO modulates the outgrowth and arborization of trigeminal axons in vivo, we followed the development of the three major trigeminal axon branches using whole-mount neurofilament immunostaining in $P T P R O^{-1-}$ embryos. No major changes were observed in the mandibular branch of E11.5 and E12.5 whole-mount stained embryos (data not shown), but we found a marked defect in one of the arbors of the ophthalmic branch. This projection normally starts to grow at E10.5, forms a highly branched arbor above the eye at E12.5 (Fig. 2A,D), and becomes fully developed, covering the entire upper half of the face by E13.5 (data not shown). In E11.5 wild-type embryos, the arbor had formed two main branches, whereas in stage-matched $P T P R O^{-/-}$embryos, there were secondary branches growing out of the main branches and the area covered by the arbor was bigger (Fig. 2A,B). Similarly, the maxillary arbor covered a bigger area in $P_{T P R O}^{-1-}$ embryos (Fig. 2B). However, the difference in the ophthalmic branch was greater than in the maxillary branch. Hence, the ratio measurement (ophthalmic/maxillary branch), designed to normalize for small developmental differences, also showed a significant increase (Fig. 2C). No significant differences were observed between wild-type and heterozygous $P T P R O^{+/-}$ embryos (Fig. $2 B, C$ ). At E12.5, we analyzed the ophthalmic projections by Sholl analysis (Gutierrez and Davies, 2007) and found an increased complexity in $P T P R O^{-/-}$embryos compared with wild-type controls, indicating a role for PTPRO as outgrowth and/or branching inhibitor (Fig. 2D,E).

Next we prepared cryosections of E12.5 embryonic heads and further analyzed the complexity of the maxillary branch to complement the quantification in the whole-mount configuration. Immunostainings for the axon marker Tuj1 revealed more numerous areas of defasciculation of the maxillary axon bundle in $P_{T P R O}^{-1-}$ embryos than in wild-type littermates (Fig. $2 F, G$ ), possibly caused by enhanced branching or defasciculation of these neurons. The areas of defasciculation were seen mainly in the proximal region of the nerve; more distal terminal arborizations were not affected (data not shown).

\section{Cultured $P T P R O^{-/-}$neurons have longer axons and are more responsive to neurotrophic factors}

To examine whether the exuberant complexity of trigeminal arbors in $P T P R O^{-1-}$ embryos is the result of enhanced responsiveness to growth-promoting signals, we prepared primary trigeminal neuron cultures and stimulated them with different neurotrophic factors. E12.5 neurons were maintained for $18 \mathrm{~h}$ in the presence of $10 \mathrm{ng} / \mathrm{ml} \mathrm{NGF}$ to promote their survival, alone or in combination with $5 \mathrm{ng} / \mathrm{ml}$ BDNF or $5 \mathrm{ng} / \mathrm{ml} \mathrm{GDNF}$ (Fig. $3 A$ ). Because PTPRO is mainly expressed in $\mathrm{TrkB}^{+}$and Ret ${ }^{+}$neurons, we expected an effect on growth and branching only in the presence of BDNF and GDNF. Indeed, stimulation with NGF alone did not show differences in outgrowth or branching between wild-type and PTPRO ${ }^{-1-}$ neurons (Fig. $3 B, C$ ). In contrast, in the presence of BDNF and GDNF, PTPRO ${ }^{-1-}$ neurons had longer axons than their respective controls (Fig. 3B). Although E12.5 neurons were mainly bipolar, BDNF stimulation triggered a sig- 

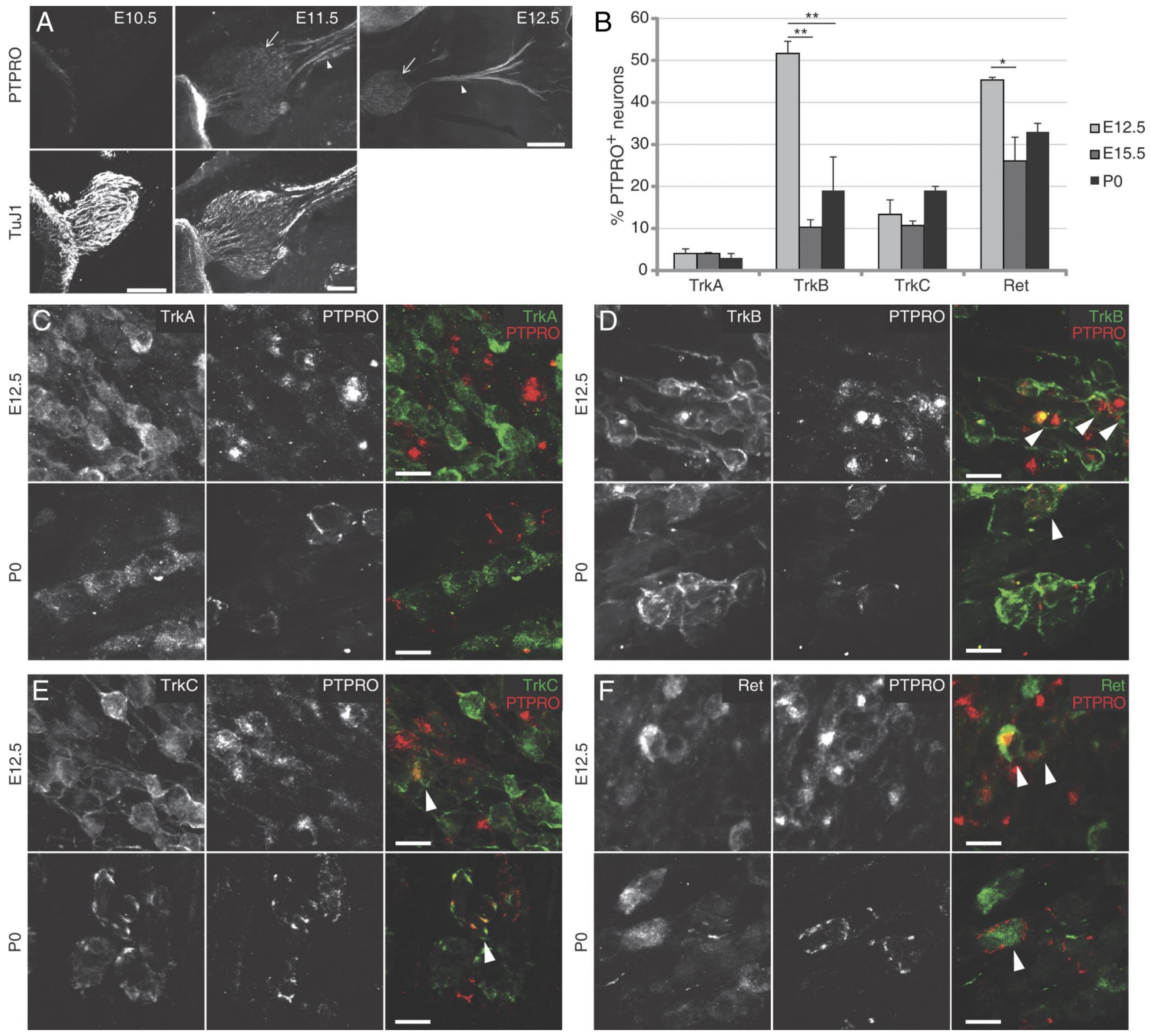

Figure 1. PTPRO expression pattern in the developing TG. A, Representative images of PTPRO and Tuj1 immunostainings of sagittal sections of E10.5, E11.5, and E12.5 TG. Arrows point to cell bodies and arrowheads to axons. Scale bar, $200 \mu \mathrm{m}$ (E10.5 and E11.5) and $400 \mu \mathrm{m}$ (E12.5). B, Graph shows mean \pm SEM of the percentage of TrkA ${ }^{+}$, TrkB $^{+}$, TrkC ${ }^{+}$, and Ret ${ }^{+}$neurons expressing PTPRO at E12.5, E15.5, and P0. For each data point, $n=3$ embryos (9 images/embryo). For each group (TrkA, TrkB, TrkC, and Ret), the percentages of neurons expressing PTPRO at different developmental stages were compared using one-way ANOVA, followed by Bonferroni's post hoc comparison test $\left.{ }^{*} p<0.05,{ }^{* *} p<0.01\right)$. C $-\boldsymbol{F}$, Confocal images showing colocalization in E12.5 and PO TG of PTPRO with TrkA (C), TrkB (D), TrkC $(\boldsymbol{E})$, and Ret $(\boldsymbol{F})$. Scale bar, $100 \mu \mathrm{m}$. Arrowheads point to neurons coexpressing PTPRO and either Trks or Ret.

nificant increase in the mean number of primary branch points (Fig. 3C). BDNF stimulation increased the number of branch points to the same extent in wild-type and $P T P R O^{-1-}$ neurons, whereas GDNF stimulation enhanced branching only in $P_{T P R O}^{-1-}$ neurons (Fig. 3C).

To better uncouple effects on axon growth from those on cell survival, we next cultured TG neurons in the presence of caspase inhibitors instead of NGF to promote their survival and scored responses to neurotrophins and GDNF at different doses. Interestingly, even in the absence of extrinsic factors, $P_{T P R O^{-/-}}$axons were longer than wild-type axons (Fig. 3D). As before, whereas treatment with NGF promoted similar outgrowth in wild-type and $P T P R O^{-1-}$ axons, BDNF and GDNF induced greater axon growth in $P T P R O^{-1-}$ neurons than in controls (Fig. $3 D$ ). For all groups, growth was stimulated most at physiological levels of neurotrophic factor $(1 \mathrm{ng} / \mathrm{ml})$. Axon branching in response to BDNF and GDNF was also enhanced in $P T P R O^{-1-}$ neurons. Strongest differences were seen at intermediate concentrations of neurotrophic factors $(10 \mathrm{ng} / \mathrm{ml})$, and the responses generally plateaued by $100 \mathrm{ng} / \mathrm{ml}$ (Fig. 3E). Stimulation with NGF at physiological concentrations produced similar axon branching responses in wild-type and $P T P R O^{-1-}$ neurons (data not shown). These results indicate that embryonic PTPRO ${ }^{-/-}$ neurons are more responsive to BDNF and GDNF, consistent with the expression of PTPRO in TrkB ${ }^{+}$and $\operatorname{Ret}^{+}$neurons.

\section{Loss of $\mathrm{TrkA}^{+}$and $\mathrm{TrkC}^{+}$neurons in $\mathrm{PTPRO}^{-/-}$newborn mice}

Because cranial sensory neurons display intrinsic differences in growth rates (Davies, 1989), the enhanced growth and arboriza- 

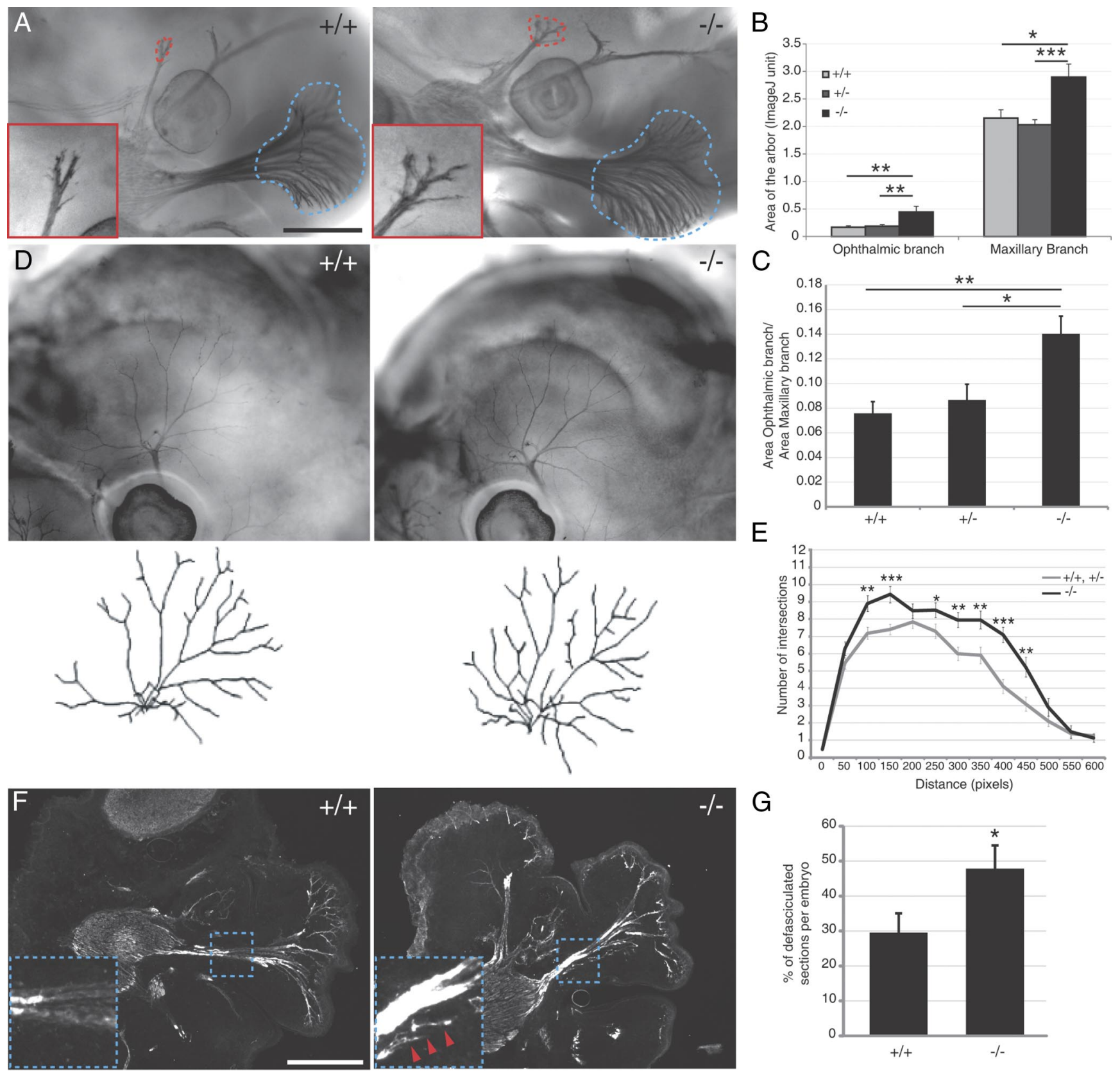

G

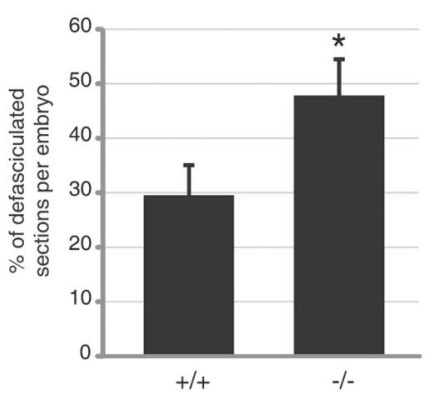

Figure 2. $P T P R 0^{-1-}$ embryos show exuberant arborization of the ophthalmic branch of the trigeminal nerve and defasciculation of the maxillary branch. $A, D$, Representative pictures of trigeminal nerve branches from whole-mount neurofilament stained E11.5 and E12.5 embryos. Red and blue dashed lines encircle the area of ophthalmic and maxillary arbors, respectively. The inset shows a higher magnification of the arbor of the ophthalmic branch that was analyzed $(\boldsymbol{A})$. Bottom panels in $\boldsymbol{D}$ show tracings of the ophthalmic arbors. $\boldsymbol{B}$, Graph represents the mean \pm SEM area of 18 wild-type, 21 PTPRO $^{+/-}$, and 15 PTPRO ${ }^{-/-}$ophthalmic and maxillary arbors. C, Graph represents the mean \pm SEM ratio of the areas covered by the ophthalmic and maxillary arbors. Numbers of embryos analyzed were the same as in $\boldsymbol{B}$. E, Sholl analysis of the ophthalmic arbor at E12.5 was done on 32 wild-type and PTPRO ${ }^{+/-}$and 24 PTPRO ${ }^{-1-}$ TG. $\boldsymbol{F}$, Tuj1 immunostaining on sagittal sections of E12.5 wild-type and PTPRO ${ }^{-1-}$ TG. The inset displays a higher magnification of the maxillary nerve. Red arrowheads point to defasciculated axons. $G$, Graph represents the percentage of sections with defasciculated axons (mean \pm SEM, $n=16$ embryos per genotype). Statistical analysis was done using two-tailed Student's $t$ test $\left({ }^{*} p<0.05,{ }^{* *} p<0.01\right.$, ${ }^{* * *} p<0.001$ ). Scale bar, $500 \mu \mathrm{m}$.

tion of a sensory nerve branch may also result from a relative increase in the numbers of fast versus slow growing neurons. Such alterations may arise from changes in cell fate or cell loss of a selective subpopulation. To test this hypothesis, we counted the numbers of TrkA ${ }^{+}, \operatorname{TrkB}^{+}, \operatorname{TrkC}^{+}$, and $\operatorname{Ret}^{+}$neurons at E12.5 and $\mathrm{P} 0$. At E12.5, the predominant subpopulation of trigeminal neurons was NGF dependent and expressed TrkA, whereas the other three subpopulations together accounted for less than half (Huang et al., 1999b) of the overall contingent (Fig. 4A, B). At P0, $\mathrm{TrkA}^{+}$neurons were still the largest subpopulation, although reduced in number compared with $\mathrm{E} 12.5$ TrkB $^{+}$neurons were unchanged in numbers compared with E12.5. $\mathrm{TrkC}^{+}$neurons were slightly reduced, and the Ret ${ }^{+}$population had increased (Huang et al., 1999a) (Fig. 4C,D). In PTPRO ${ }^{-1-}$ embryos, the distribution of neuronal subpopulations was not significantly different from controls (Fig. 4B), suggesting that the absence of PTPRO did not affect the cell fate of these neurons. At P0, there was a small but significant reduction in the numbers of $\operatorname{TrkA}{ }^{+}$ and $\mathrm{TrkC}^{+}$neurons and no significant change in $\mathrm{TrkB}^{+}$and Ret $^{+}$neurons (Fig. 4D). Staining for the general neuronal marker 

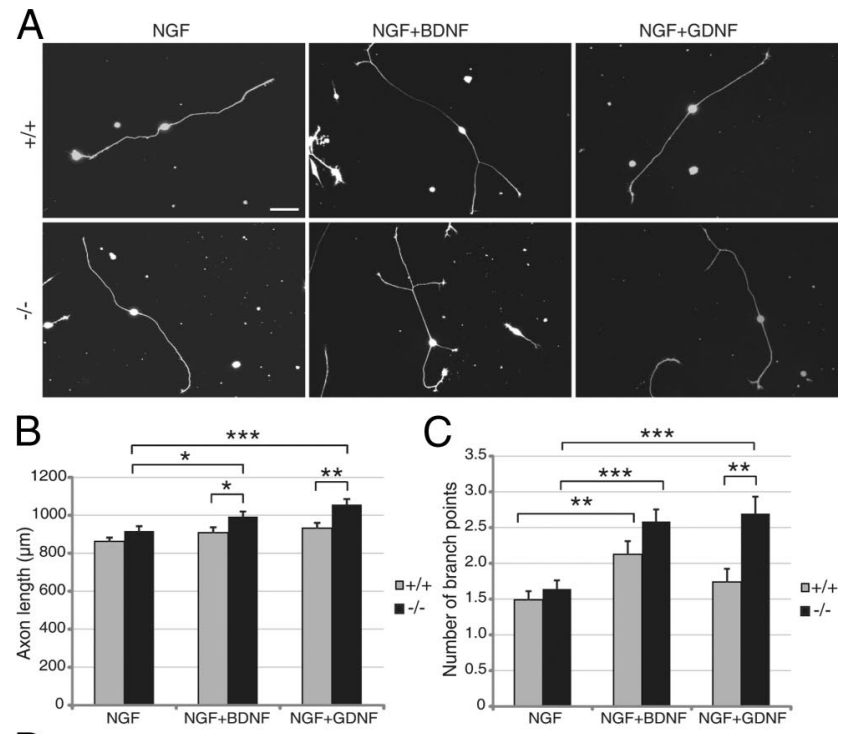

D

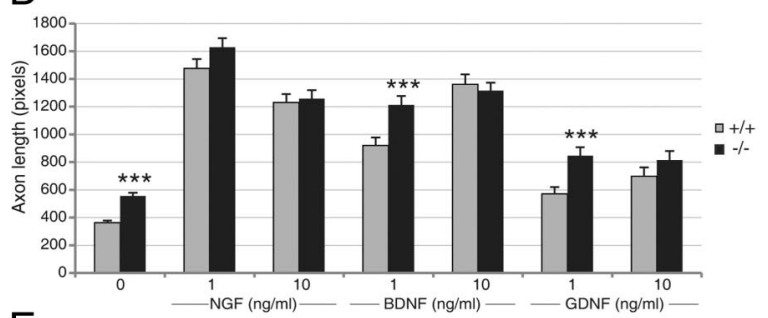

E

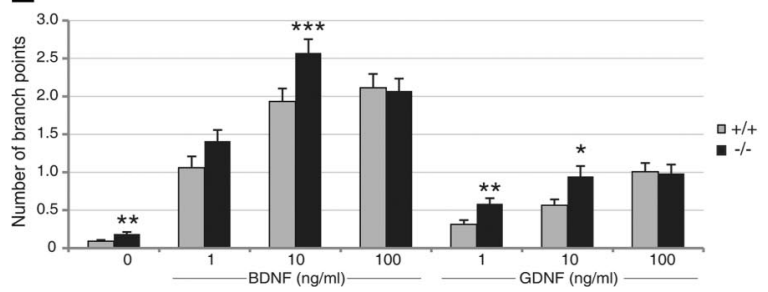

Figure 3. Cultured PTPRO ${ }^{-1-}$ trigeminal neurons are more sensitive to BDNF and GDNF but not NGF stimulation. $\boldsymbol{A}$, Representative pictures of E12.5 trigeminal neurons, stimulated with growth factors as indicated. Scale bar, $100 \mu \mathrm{m}$. Quantification of the length of the axons $(\boldsymbol{B})$ or the number of branching points $(\boldsymbol{C})$ of neurons stimulated as indicated on the $x$-axis. Graphs represent mean \pm SEM. Numbers of trigeminal neurons analyzed from at least three independent cultures: for NGF stimulation, 200 neurons (wild type) and 195 neurons (PTPRO ${ }^{-/}$); for BDNF and GDNF stimulation, 150 neurons per genotype. $\boldsymbol{D}, \boldsymbol{E}$, The length of axons and the number of branching points in response to increasing amounts of NGF, BDNF, and GDNF in the presence of caspase inhibitors (10 $\mu \mathrm{m}$ Q-0ph-VD) were measured in dissociated trigeminal cultures. Numbers of trigeminal neurons analyzed: no stimulation, 550 neurons; NGF stimulation, 150 neurons; BDNF and GDNF stimulation, 200 neurons per genotype. Statistical analysis was done as for Figure 2.

$\mathrm{NeuN}$ at E12.5 and P0 did not reveal changes in the total numbers of neurons (Fig. $4 A-D$ ). Together, these results suggest that changes in cell fate and survival do not contribute significantly to the exuberant growth of E12.5 embryonic trigeminal axons.

\section{PTPRO regulates TrkB and Ret signaling}

Next we asked whether PTPRO interacts directly with TrkB and Ret and exerts its growth-suppressive function by suppressing TrkB and Ret kinase signaling. We tried to examine colocalization of PTPRO with RTKs in cultured neurons but were unable to detect PTPRO with sufficient subcellular resolution with the available antibodies. As an alternative, we investigated colocalization and activation of these proteins in cell culture, overexpress- ing mPTPRO. When TrkB and mPTPRO were coexpressed, the two receptors strongly colocalized on the cell surface but much less so in the cell interior (Fig. 5A and data not shown). Overexpression of TrkB in HeLa cells led to ligand-independent activation (Shintani and Noda, 2008), as shown by anti-phosphotyrosine immunostaining (Fig. 5B). In the presence of PTPRO, the intensity of phosphotyrosine immunostaining was markedly reduced (Fig. 5C,D). Moreover, BDNF-induced autophosphorylation of TrkB and ERK1/2 phosphorylation were strongly suppressed by coexpressed mPTPRO (Fig. 5E-G).

Ret has two main isoforms: Ret9 and Ret51. Because they elicit similar responses to GDNF stimulation in sympathetic neurons (Encinas et al., 2008), we used only Ret51 for the following in vitro experiments. In the case of Ret, colocalization with MPTPRO was as strong as for TrkB, and the degree of colocalization in transfected HeLa cells was enhanced by stimulation with GDNF and soluble GFR $\alpha 1$ (Fig. 6A,D,E). However, the increase in colocalization was detectable only when cells were permeabilized, suggesting that mPTPRO and Ret may colocalize in intracellular compartments, for example, endosomes, during stimulation. Stimulation with GDNF and soluble GFR $\alpha 1$ also increased the intensity of phosphotyrosine staining, and this increase was suppressed by the presence of MPTPRO (Fig. $6 B-D, F$ ). In transfected HEK293 cells, basal Ret autophosphorylation, which was visualized by immunoblotting with anti-phosphotyrosine antibodies, was high and was not increased by GDNF stimulation but was strongly suppressed by coexpression of mPTPRO (Fig. 6GI). mPTPRO effects on overall Ret tyrosine phosphorylation were significant but stronger on Ret phosphotyrosine 1062, suggesting that PTPRO may dephosphorylate only a subset of tyrosine residues present on the receptor (Fig. 6G,I). This strong inhibition of Ret kinase activity correlated well with a pronounced inhibition of GDNF-induced ERK phosphorylation (Fig. 6G,J).

Finally, we checked whether PTPRO coexpression influenced surface levels of Ret and TrkB in the presence and absence of their ligands. During stimulation with BDNF for $5 \mathrm{~min}$, TrkB expression on the surface slightly increased, and no differences were observed if PTPRO was coexpressed. During stimulation with GDNF, Ret was internalized. Also in this case, we did not observe significant differences in Ret distribution when PTPRO was coexpressed (data not shown).

Together, these results suggest that PTPRO regulates TrkB and Ret kinase activity and signaling, supporting the role of PT$\mathrm{PRO}$ as a negative regulator of BDNF- and GDNF-induced axon growth and branching.

\section{PTPRO does not regulate Eph kinase activity and signaling}

To examine whether the exuberant complexity of axonal arbors in $\mathrm{PTPRO}^{-/-}$embryos might also result from altered responsiveness to specific repellent signals, we investigated whether Eph tyrosine kinase signaling was affected. cPTPRO is a known regulator of Eph signaling in the retinotectal system (Shintani et al., 2006), and several Eph family members are expressed in the TG (Luukko et al., 2005). TG explant cultures from E12.5 mouse embryos were stimulated with soluble ephrinA5 fused to the Fc portion of human IgG (ephrinA5-Fc) or with control Fc and stained with phalloidin to visualize the growth cones (Fig. 7A). Stimulation with ephrinA5-Fc led to a marked increase in the numbers of collapsed growth cones of TG neurons, but there was no difference in the rate of collapse between wild-type and $\mathrm{PTPRO}^{-1-}$ explants (Fig. $7 \mathrm{~B}$ ), arguing against an impairment of Eph signaling as the cause of the increased complexity of TG axonal arbors. To explore in vivo whether Eph signaling is regu- 
A

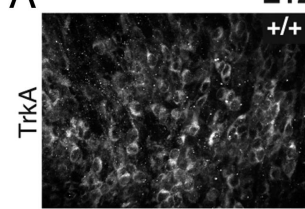

E12.5
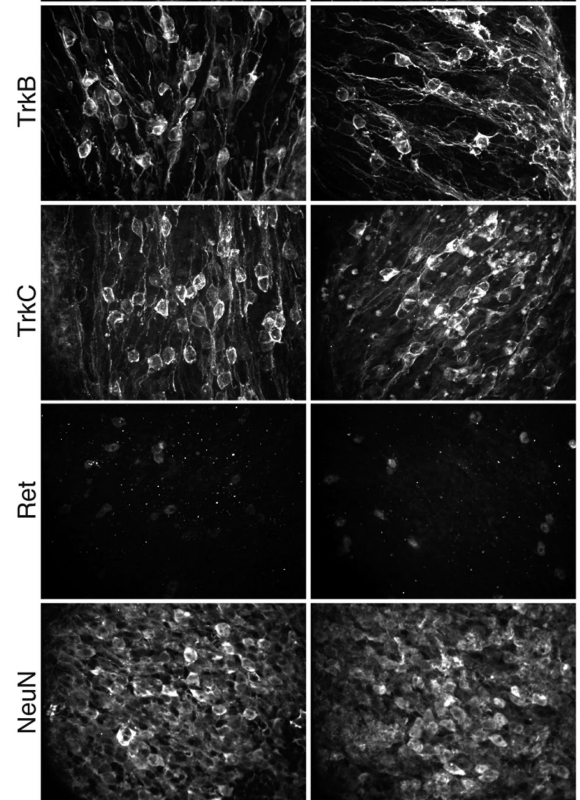

B
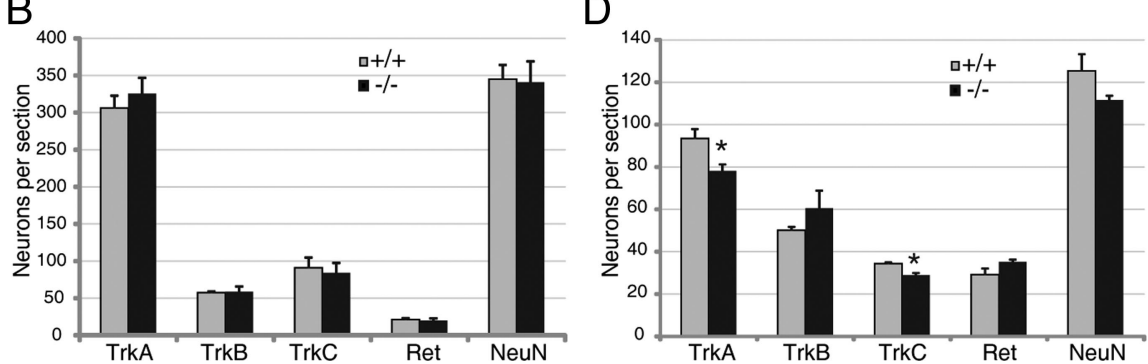

Figure 4. $P T P R O^{-1-}$ embryos do not have defects in neuronal differentiation, but there is a loss of TrkA ${ }^{+}$and TrkC ${ }^{+}$neurons at P0. $\boldsymbol{A}, \boldsymbol{C}$, Immunostainings for TrkA, TrkB, TrkC, Ret, and NeuN on cryosections from E12.5 $(\boldsymbol{A})$ and newborn $(\boldsymbol{C})$ wild-type and PTPRO $^{-/-}$TG. Scale bars, $50 \mu \mathrm{m} . \boldsymbol{B}, \boldsymbol{D}$, Graphs represent the average number (mean $\pm \mathrm{SEM}, n=3-4$ embryos, $9-20$ images/ embryo) of TrkA ${ }^{+}$, TrkB $^{+}{ }^{+}, \operatorname{TrkC}^{+}{ }^{+}$, Ret $^{+}$, and NeuN ${ }^{+}$neurons per section. Statistical analysis was done as for Figure 2.

lated by PTPRO (Shintani et al., 2006), we analyzed the retinocollicular projection in $P T P R O^{-1-}$ mice at P8. Although PTPRO is expressed in the retina at $\mathrm{P0}$ (data not shown), there were no obvious topographic targeting defects or ectopic branching of RGC axons in $P T P R O^{-/-}$mice compared with littermate controls (Fig. 7C).

These results suggested that $\mathrm{MPTPRO}$ and chick PTPRO (cPTPRO) may have different substrate specificities. To test this hypothesis further, we examined the responsiveness to ephrins in another mouse neuronal population, namely limb innervating (LMC) motor neurons, and the rate of EphA4 dephosphorylation by either MPTPRO or CPTPRO. We stimulated explants of lumbar motor neurons from $\mathrm{Hb}$-GFP ${ }^{+}$transgenic embryos (Wichterle et al., 2002) with different doses of either control Fc or a 1:1 mix of ephrinA2 and ephrinA5-Fc, and ephrinB2-Fc. Both subtypes of ephrins markedly increased the fraction of collapsed growth cones in the explant, regardless of the presence or absence of PTPRO (Fig. $7 D, E$ and data not shown). These results demonstrate that $P T P R O^{-1-}$ LMC motor neurons are not more sensitive to ephrin stimulation, despite the fact that PTPRO is
PO
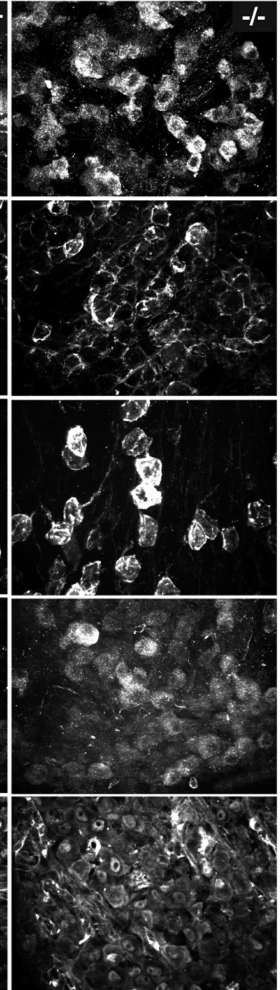

.

prominently expressed in both subpopulations of LMC neurons (data not shown). Also, in vivo, guidance of the lateral cohort of LMC motor axons to the dorsal limb, though critically dependent on ephrinA/ EphA4 signaling (Helmbacher et al., 2000; Eberhart et al., 2002; Kramer et al., 2006) is unaffected in $\mathrm{PTPRO}^{-/-}$embryos. The evidence includes quantification of axon bundle diameters in neurofilament wholemount stained embryos and axon tracings with rhodamine-dextran (RD) injected into the ventral or dorsal hindlimb as described previously (Kramer et al., 2006; Dudanova et al., 2012) (Fig. 7F-I and data not shown). To examine the substrate specificity of PTPRO, HEK293 cells coexpressing either mPTPRO or CPTPRO with mouse EphA4 were stimulated with control Fc or ephrinA4-Fc, and EphA4 autophosphorylation was assessed by Western blotting. Interestingly, only cPTPRO, was able to significantly dephosphorylate EphA4 (Fig. $7 J, K)$. These results indicate that mPTPRO does not regulate Eph signaling and suggest that mPTPRO and cPTPRO have different substrate specificities.

\section{Discussion}

Here we have shown that PTPRO, a receptor tyrosine phosphatase, is expressed in a large fraction of $\mathrm{TrkB}^{+}$and Ret ${ }^{+}$mechanoreceptors within the TG during embryogenesis. In $P$ TPRO ${ }^{-/-}$mice, TG axons grow longer and exuberant branches, suggesting that PTPRO suppresses the response to endogenous growth factors. Furthermore, cultured $P$ TPRO ${ }^{-1-}$ TG neurons show more BDNF- and GDNF-induced axonal outgrowth and branching than control neurons, indicating that PTPRO regulates the activity of TrkB and Ret receptors. This role of PTPRO is also seen in the chick system, suggesting that this function is evolutionarily conserved. Although PTPRO has been shown to regulate Eph signaling in the chick retinotectal system, we find that mouse PTPRO fails to do so in several neuronal systems in vivo and in vitro, suggesting that the regulation of Eph receptor-mediated developmental processes by RPTPs has diverged between chick and mouse.

\section{PTPRO modulates growth factor responses}

Our work revealed a role for PTPRO as a negative modulator of TG axon growth and branching in response to specific growth factor stimulation. PTPRO is excluded from the largest population of TG neurons, TrkA ${ }^{+}$nociceptive neurons, and the response of cultured $P T P R O^{-/-}$TG neurons to exogenously added NGF is not different from wild type. In contrast, the strong response of cultured PTPRO ${ }^{-/-}$TG neurons to BDNF and GDNF correlates well with the prominent expression of PTPRO in $\mathrm{TrkB}^{+}$and $\mathrm{Ret}^{+}$neurons. These results strongly suggest that PTPRO has a cell-autonomous role in constraining TG neuron growth and branching. Interestingly, the loss of PTPRO affects neuron growth and branching at lower concentration of BDNF 

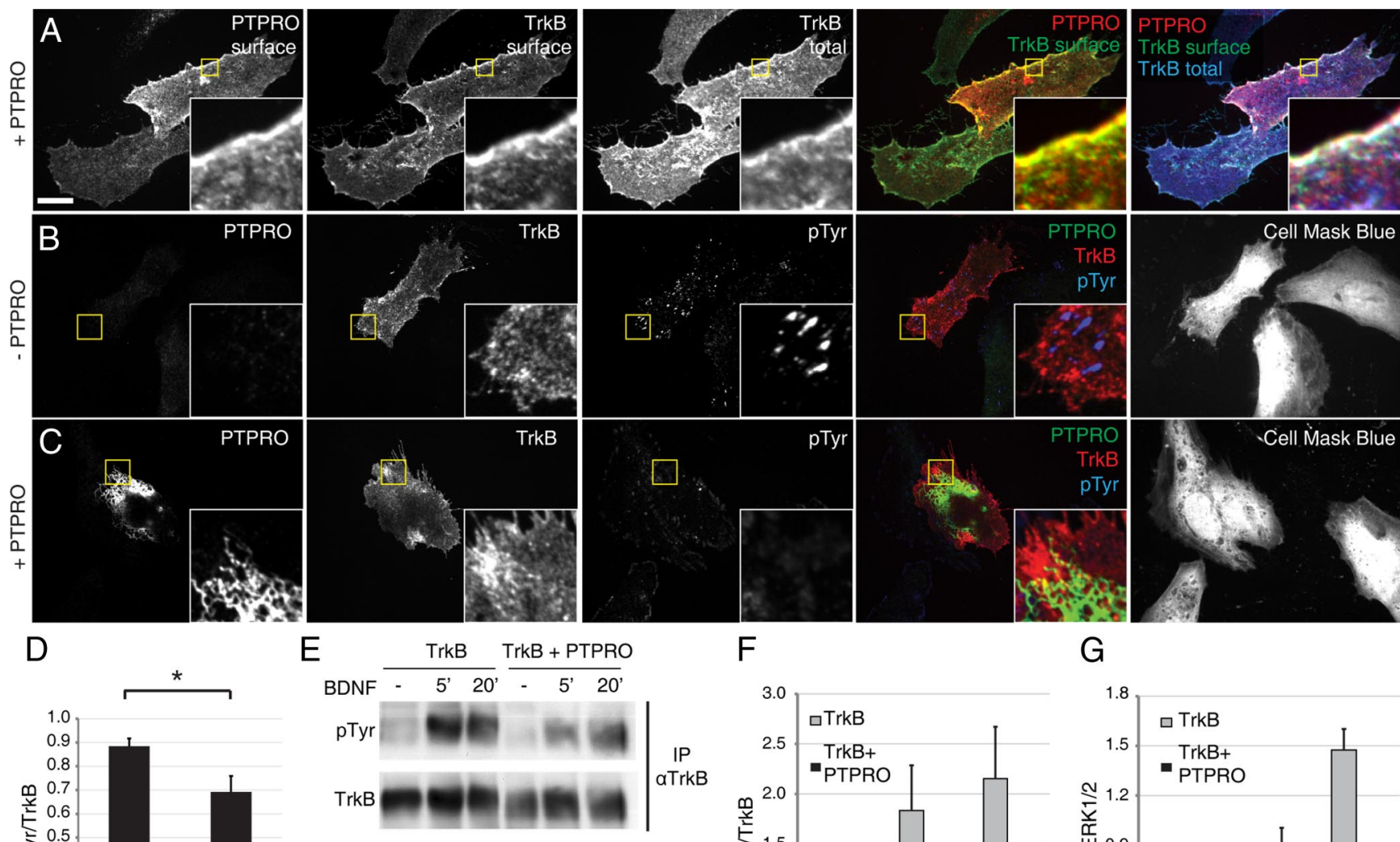

$\mathrm{F}$

G
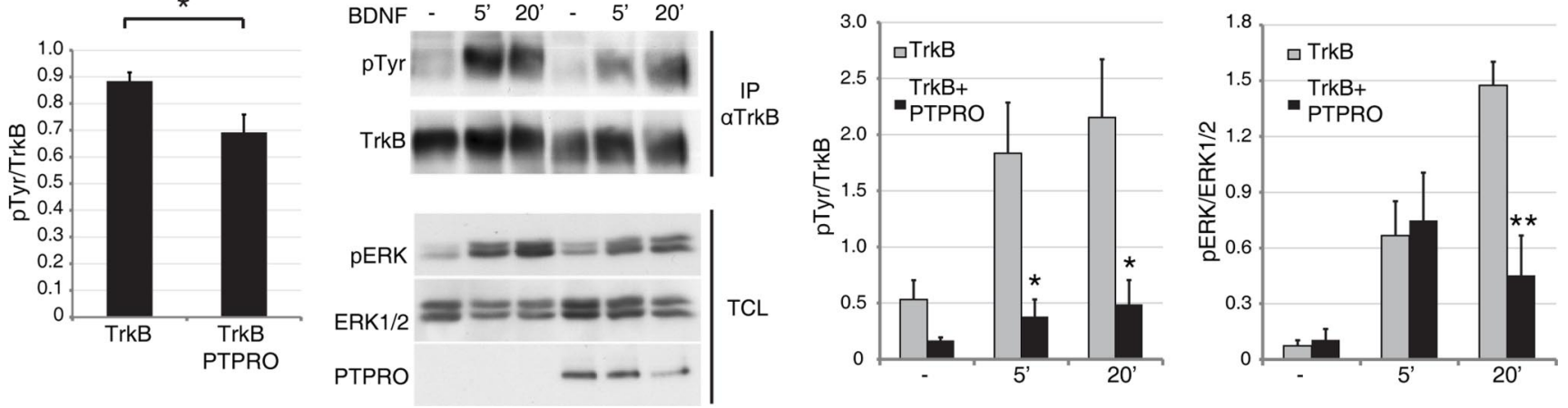

Figure 5. PTPRO dephosphorylates TrkB. $A$, HeLa cells transfected with TrkB and PTPRO and immunostained to detect surface expression of PTPRO (PTPRO surface) and TrkB (TrkB surface) and total expression of TrkB (TrkB total). B,, , HeLa cells transfected with TrkB with $(\boldsymbol{C}$ ) or without $(\boldsymbol{B}) \mathrm{mPTPRO}$-Flag and immunostained for Flag (PTPRO), TrkB, and phosphotyrosine (pTyr). Cells outlines are labeled with Cell Mask Blue. Insets are higher-magnification images of the areas marked with a box. Scale bar, $20 \mu \mathrm{m}$. D, Graph represents the intensity of phosphotyrosine (pTyr) staining normalized by the intensity of TrkB staining (mean \pm SEM). Number of cells analyzed: 26 cells for TrkB and 29 cells for TrkB and PTPRO from 3 independent experiments. E, Western blots of HEK293 cells transfected with TrkB with or without mPTPRO-Flag and stimulated as indicated. Total cell lysates (TCL) were probed against phospho-ERK (pERK), ERK1/2, and Flag (PTPRO). Immunoprecipitates of TrkB (IP $\alpha$ TrkB) were probed against pTyr and TrkB. $\boldsymbol{F}, \boldsymbol{G}$, Graphs represent TrkB autophosphorylation levels $(\boldsymbol{F})$ and ERK phosphorylation $(\boldsymbol{G})$. Three independent experiments were performed, and the intensities of the phospho bands were quantified using NIH ImageJ and normalized by the total levels of the proteins. Statistical analysis was done as for Figure 2.

and GDNF, hinting at the requirement of the phosphatase in setting a functional threshold in response to neurotrophin stimulation. Genetic ablation of PTPRO does not change the maximal effect of the response but rather shifts the dose-response curve to the left (higher sensitivity to neurotrophin stimulation).

Mechanistically, we show that PTPRO suppresses ligandinduced autophosphorylation of TrkB and Ret and that Ret activation enhances colocalization with PTPRO, suggesting that these RTKs are direct substrates of PTPRO in living cells. Alternatively, PTPRO may target other tyrosine phosphorylated downstream effectors of these RTKs (see below). Moreover, we show that ligand-induced activation of ERK signaling is suppressed by coexpression of PTPRO. This result is consistent with the known function of ERK signaling in sensory axon growth (Markus et al., 2002; Zhong et al., 2007).

The function of PTPRO as a negative modulator of RTK signaling is reminiscent of RPTP $\sigma$, a class IIa RPTP, which limits neurite outgrowth of DRG sensory neurons by directly dephosphorylating either TrkA and TrkC receptors (Faux et al., 2007) or the cell adhesion molecule N-cadherin (Siu et al., 2007). Similar to TG neurons in $P T P R O^{-/-}$, DRG neurons in $R_{P T P \sigma^{-/-}}$mice exhibit faster growth rates ex vivo (Siu et al., 2007), but in vivo sensory axon development has not been analyzed. Negative modulation of neurotrophic factor receptors is not restricted to RPTPs. Lrig1, a transmembrane proteins with LRRs in its ectodomain, abolishes GDNF/Ret-induced axon outgrowth by inhibition of GDNF binding and recruitment of Ret to lipid rafts (Ledda et al., 2008).

RPTPs and LRR proteins can also be positive regulators of RTK signaling. Leukocyte common antigen-related (LAR) RPTP enhances TrkB signaling by dephosphorylation and activation of Src downstream of TrkB. $L A R^{-1-}$ hippocampal neurons display reduced TrkB signaling and diminished BDNF-induced survival (Yang et al., 2006). More recently, LAR was shown to bind heparan sulfate proteoglycans to mediate attractive guidance of sensory axons to the skin; however, the signaling mechanism underlying this function is unknown (Wang et al., 2012). The LRR protein Linx positively modulates NGF/TrkA and GDNF/ Ret signaling, possibly by promoting ERK signaling. Axonal defects in Linx mutants resemble those in mice lacking NGF, TrkA, and Ret (Mandai et al., 2009). The neurotrophin receptor p75, which can directly interact with Trks (Dechant, 2001), is also 

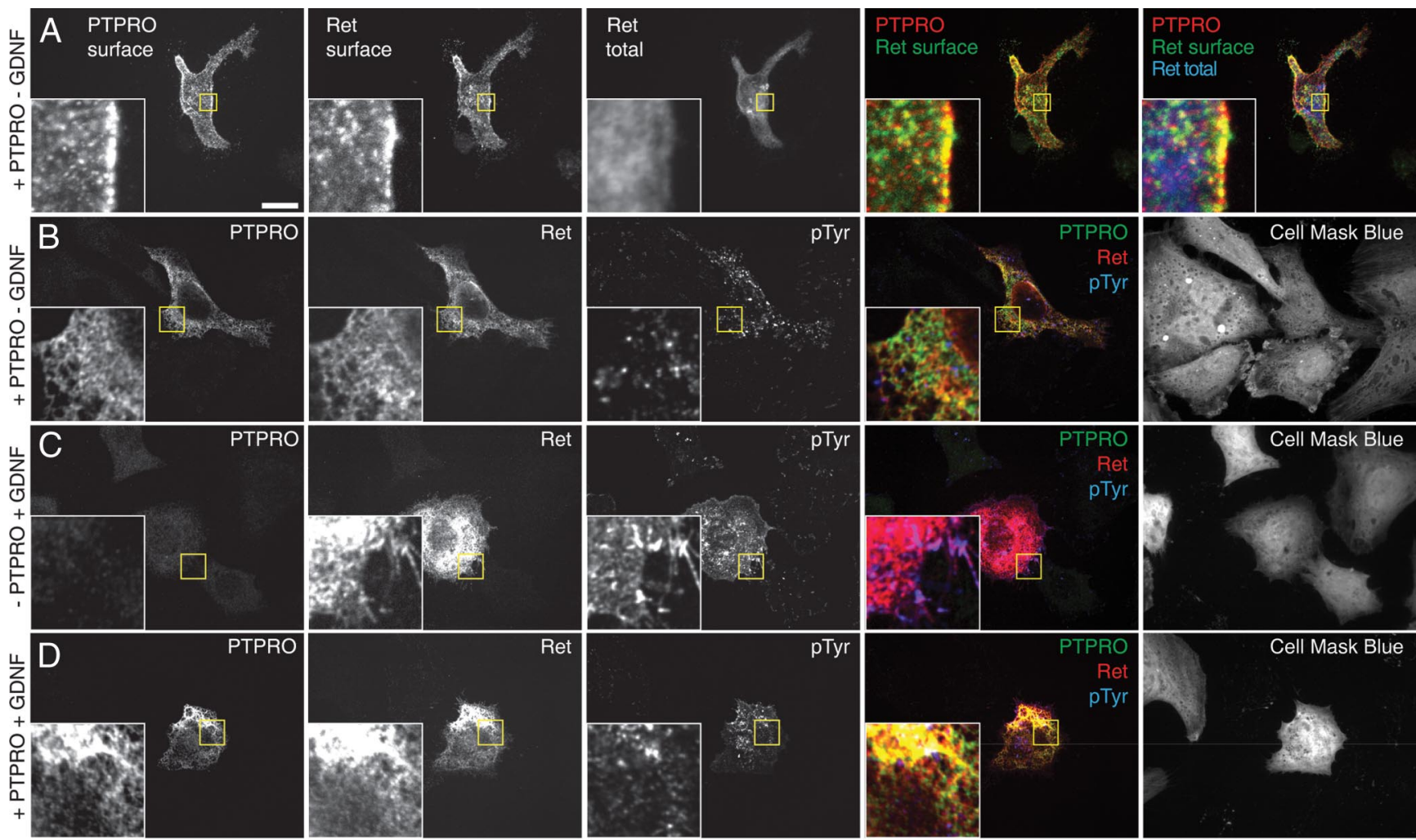

$\mathrm{E}$

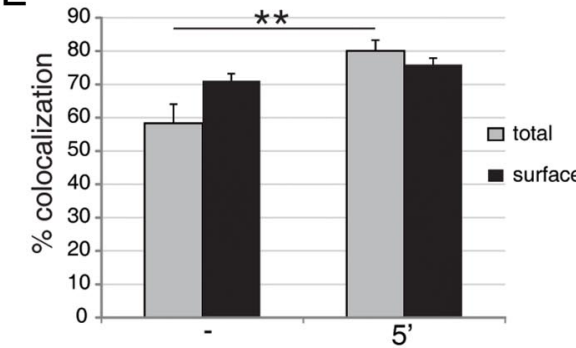

F

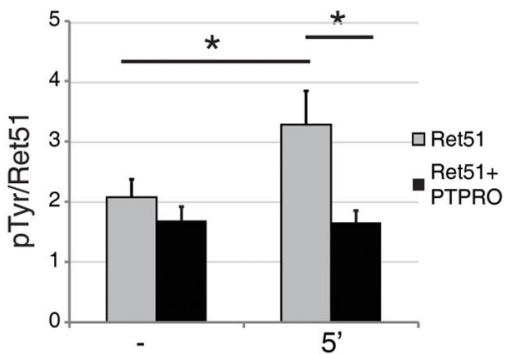

G

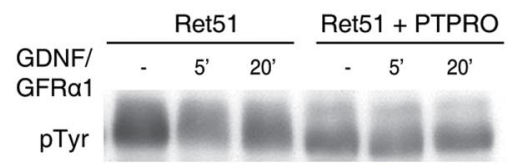

Ret

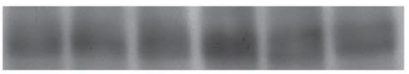

pY1062
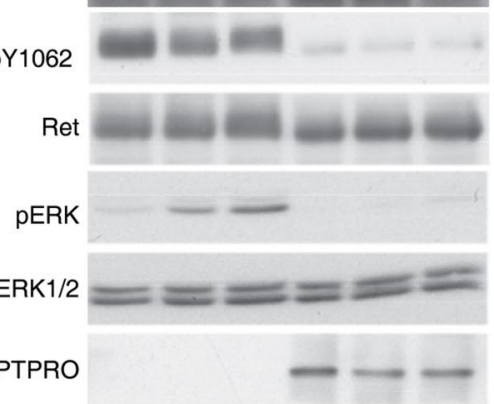

$\mathrm{H}$
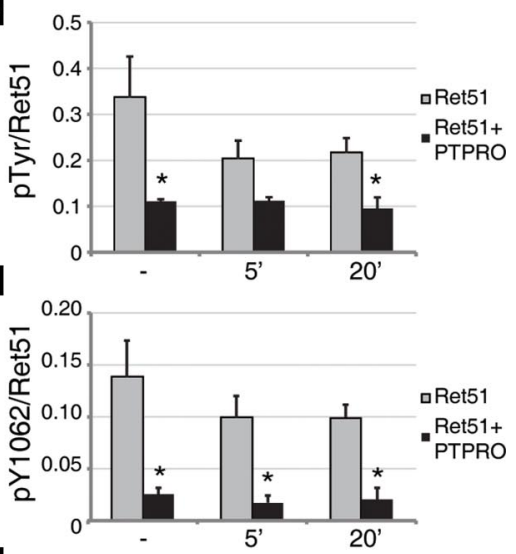

$J$

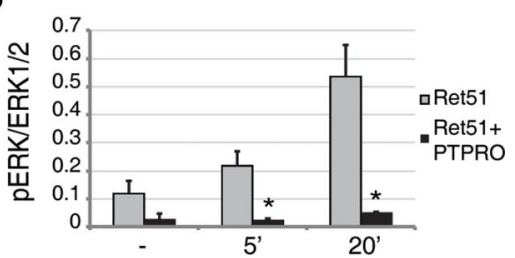

Figure 6. PTPRO dephosphorylates Ret. $A$, HeLa cells transfected with Ret51 and PTPRO and immunostained to detect surface expression of PTPRO (PTPRO surface) and Ret (Ret surface) and total expression of Ret (Ret total). $\boldsymbol{B}-\boldsymbol{D}$, HeLa cells transfected with Ret51 and with ( $\boldsymbol{B}, \boldsymbol{D})$ or without ( $(\mathbf{m P T P R O}$-Flag and stimulated as indicated. Fixed cells were stained with anti-Flag (PTPRO), anti-Ret, and pTyr antibodies and marked with Cell Mask Blue. Scale bar, $20 \mu \mathrm{m}$. $\boldsymbol{E}$, Graph represents the degree of colocalization of Ret and PTPRO (mean \pm SEM) before and after GDNF stimulation, with (total) or without (surface) cell permeabilization. Numbers of cells analyzed after permeabilization (total staining): 23 cells before and 14 cells after stimulation from at least 3 independent experiments. Numbers of cells analyzed without permeabilization (surface staining): 13 cells before and 23 cells after stimulation from 3 independent experiments. $\boldsymbol{F}$, Graph represents $p$ Tyr staining intensity normalized by the intensity of Ret staining (mean \pm SEM). Numbers of cells analyzed: 48 cells before and 26 cells safter stimulation for Retalone, and 36 cells before and 26 cells after stimulation for Ret and PTPRO, fromatleast 3 independentexperiments. G, Western blots of HEK293 cells transfected with Ret, with or without mPTPRO-Flag, and stimulated as indicated. TCL were probed against phosphotyrosine (pTyr), Ret phosphotyrosine 1062 (Ret pY1062), Ret, pERK, ERK1/2, and Flag (PTPRO). $\boldsymbol{H}-J$, Graphs represent Ret autophosphorylation levels $(\boldsymbol{H}, \boldsymbol{I})$ or ERK phosphorylation $(\boldsymbol{J})$. Quantification of phosphorylation was done as for Figure 5, and statistical analysis was done as for Figure 2 .

important for growth of the ophthalmic branch and sensory axons to the limbs (Bentley and Lee, 2000; Ben-Zvi et al., 2007); it is currently unknown whether the interaction of p75 with Trk receptors is essential for this in vivo function. PTPRO and other RTK interactors seem to have evolved to fine tune growth factor signaling in opposing manners and in a celltype-specific manner. These proteins therefore increase the diversity of signaling output of a limited number of RTKs and 

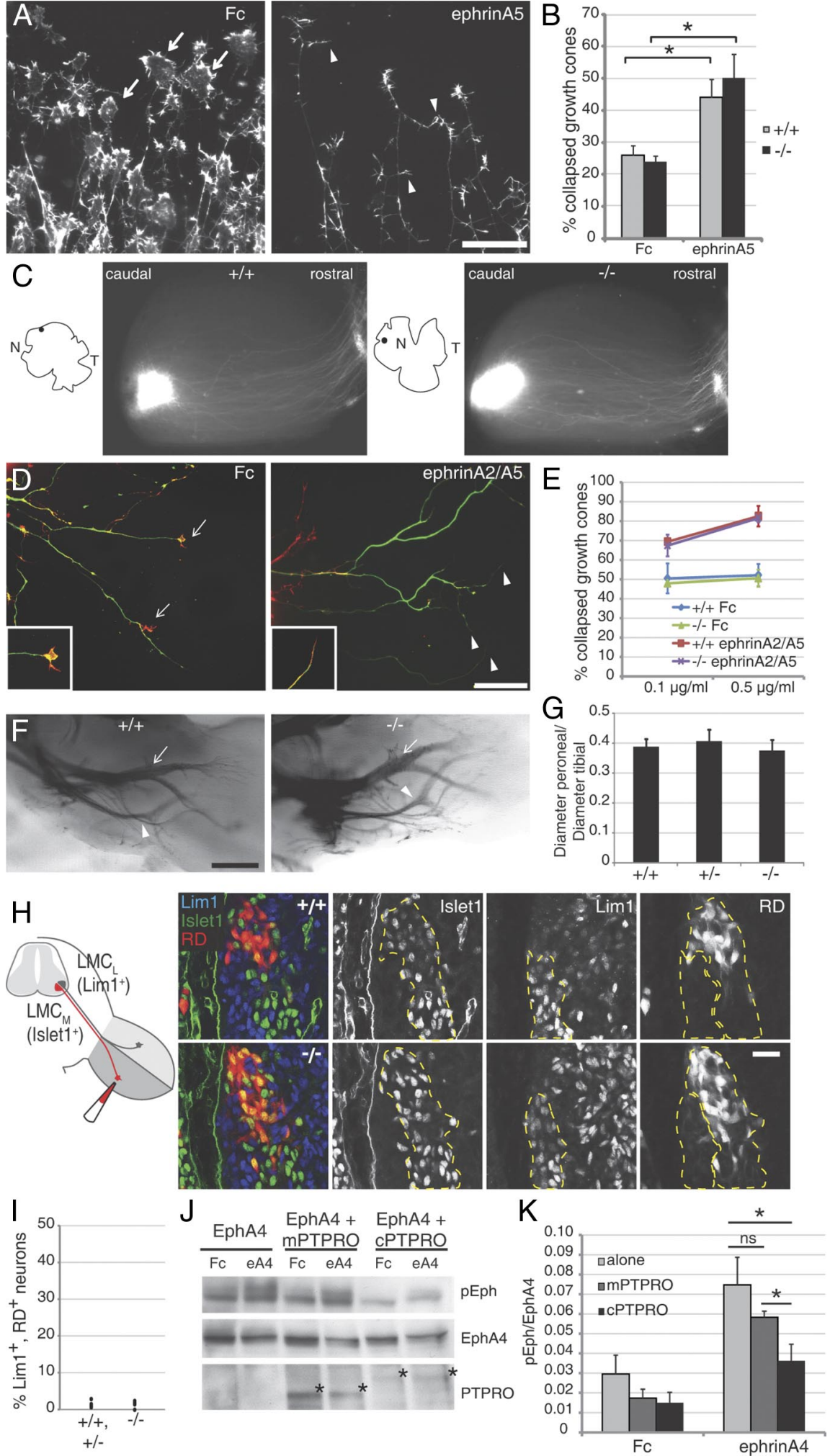

Figure 7. Eph signaling is not affected in PTPRO ${ }^{-1-}$ embryos. $A$, Representative pictures of trigeminal neuron explant cultures stimulated with $0.5 \mu \mathrm{g} / \mathrm{ml}$ preclustered $\mathrm{Fc}$ (negative control) or preclustered ephrinA5. Explants were stained with Phalloidin568. Arrows point to non-collapsed growth cones, and arrowheads show collapsed growth cones. Scale bar, $100 \mu \mathrm{m}$. B, Graph represents the percentage of collapsed growth cones. Four to six explants per condition were analyzed from three embryos per genotype. C, Representative pictures for the analysis of the retinocollicular projection in wild-type and PTPRO $^{-1-}$ mice at P8. Injection of Dil into a small area of nasal retina (drawings on left side) result in labeling of topographically appropriate termination zones in the caudal part of the superior colliculus. Numbers of animals analyzed for the termination zone were 7 wild-type, 12 $\mathrm{PTPRO}^{+/-}$, and $5 \mathrm{PTPRO}^{-/-}$. Numbers of animals analyzed for ectopic branching were three wild-type, four $P T P R 0^{+/-}$, and four $\mathrm{PTPRO}^{-1-}$. D, Representative pictures of motor neuron explant cultures stimulated with $\mathrm{Fc}$ (as a control) or ephrins. Arrows growth factors to control the branch morphology and connectivity of developing neurons.

\section{PTPRO and modulation of repulsive cues}

We also explored the possibility that PTPRO modulates responses to repulsive guidance cues, thereby limiting axon branching. Repulsive guidance cues, such as members of the Slit family, have been shown previously to positively modulate sensory axon branching (Ma and TessierLavigne, 2007). Moreover, PTPRO was initially characterized as negative regulator of repulsive Eph signaling in the chick retinotectal system (Shintani et al., 2006). Gainand loss-of-function (shRNA knockdown) studies established a role for PTPRO in retinotectal projection guidance in vivo, presumably involving Eph regulation (Shintani et al., 2006). Several lines of evidence suggest that mouse PTPRO does not control Eph signaling: (1) ex vivo cultures of $P T P R O^{-/-}$ and control TG neurons are equally sensitive to ephrin-induced growth cone collapse; (2) the retinotopic maps in

\footnotetext{
and arrowheads point to non-collapsed and collapsed growth cones, respectively. In green is the Hb9-GFP and in red the Phalloidin-568 staining. Scale bar, $200 \mu \mathrm{m}$. $\boldsymbol{E}$, Graph represents the percentage of collapsed growth cones. Three to six explants per condition were analyzed from four embryos per genotype. Compared with the respective controls, all the ephrinA2/A5 stimulated explants show a statistically significant increase in the percentage of growth cone collapse $(0.1 \mu \mathrm{g} / \mathrm{ml}$ ephrin-Fcon wild-type cultures, $p=0.038 ; 0.5 \mu \mathrm{g} / \mathrm{ml}$ on wild type, $p=0.008 ; 0.1 \mu \mathrm{g} / \mathrm{ml}^{\text {on PTPRO }}{ }^{-/-}, p=0.007 ; 0.5$ $\left.\mu \mathrm{g} / \mathrm{ml}_{\text {on PTPRO }}{ }^{-1-}, p=0.002\right) . \boldsymbol{F}$, Representative pictures of neurofilament stained E12.5 whole-mount embryos. Arrowheads point to the peroneal nerve; arrows point to the tibial nerve. $\mathbf{G}$, Graph represents the ratios between the diameter of the peroneal and the tibial nerves of 16 wild-type, 12 $\mathrm{PTPRO}^{+/-}$, and $15 \mathrm{PTPRO}^{-/-}$hindlimbs (mean \pm SEM). $\boldsymbol{H}$, Single confocal plane of ventral retrograde tracings in E12.5 embryos. RD was injected in the ventral shank of the hindlimb, and sections were stained with Islet1 and Lim1 to label the medial $\left(L M C_{M}\right)$ and lateral $\left(L M C_{L}\right)$ cohorts (populations are delimited by a dashed lines), respectively. Scale bar is $50 \mu \mathrm{m}$. I, Graph represents the percentage of misprojections (neurons positive for RD and Lim1 staining) in relation to all RD-labeled cells in ventral retrograde tracings of six wild-type or PT$\mathrm{PRO}^{+/-}$and eight PTPRO $^{-1-}$ embryos. J, Western blots of HEK293 cells cotransfected with EphA4 and mPTPRO or CPTPRO isoforms of PTPRO-Flag and stimulated as indicated. Total cell lysates (TCL) were probed against phospho- and total EphA4 and Flag. Asterisks indicate PTPRO bands; mPTPRO runs at $140 \mathrm{kDa}$ and $\mathrm{CPTPRO}$ at $160 \mathrm{kDa}$. $\boldsymbol{K}$, Graph represents the levels of EphA4 autophosphorylation (mean \pm SEM) after control Fc and ephrinA4-Fc stimulation. The experiment was done in triplicate, and the intensities of the phospho bands were quantified using NIH ImageJ and normalized by the total level of the proteins. Statistical analysis was done as for Figure 2.
} 
$\mathrm{PTPRO}^{-/-}$mice were indistinguishable from control mice; (3) limb motor axons, which are sensitive to Eph/ephrin signaling (Bonanomi and Pfaff, 2010), did not show projections defects in $\mathrm{PTPRO}^{-/-}$embryos in vivo and were not more sensitive to ephrins ex vivo; and (4) cPTPRO, but not mPTPRO, is able to dephosphorylate EphA4 in living cells. These results suggest that $\mathrm{MPTPRO}$ either does not control Eph activity in the retinocollicular system or is functionally redundant with other phosphatases that regulate Eph activity (Nievergall et al., 2010). MPTPRO and CPTPRO are divergent enough ( $80 \%$ similarity) to have different substrate specificities, as was shown previously for mouse and human RPTPo (Hou et al., 2011). Future structurefunction work to elucidate the molecular basis of substrate specificity of mPTPRO versus cPTPRO would be interesting to help shed light into this rather unexplored question.

\section{Non-cell-autonomous roles of PTPRO?}

Previously, $P T P R O^{-1-}$ mice were shown to have decreased numbers of a subset of nociceptive (calcitonin gene-related peptide ${ }^{+}$) DRG neurons at birth and as adults (Gonzalez-Brito and Bixby, 2009). In addition, the central projections of the surviving nociceptive and proprioceptive (parvalbumin ${ }^{+}$) DRG neurons were abnormal, and PTPRO ${ }^{-1-}$ mice performed abnormally on tests of thermal pain and sensorimotor coordination (Gonzalez-Brito and Bixby, 2009). Here we show that, during early embryonic development, PTPRO is rarely coexpressed with TrkA or TrkC, antigens that are early markers of nociceptive and proprioceptive neurons. Moreover, $P$ TPRO ${ }^{-/-}$trigeminal cultures do not show aberrant sensitivity toward exogenous NGF. However, at birth, expression of PTPRO increases in $\mathrm{TrkC}^{+}$neurons, and $\mathrm{PTPRO}^{-/-}$mice show partial loss of $\mathrm{TrkA}^{+}$and $\mathrm{TrkC}^{+}$sensory neurons. Thus, the observed changes in nociceptive and proprioceptive subpopulations may at least in part be attributable to non-cell-autonomous functions of PTPRO. Whether PTPRO has a pro-survival function or affects cell differentiation remains to be clarified. PTPRO is also expressed at the spinal cord midline and in the dorsal root entry zone of DRG axons in the spinal cord (data not shown and Beltran et al., 2003), and its removal could non-cell autonomously affect the positioning of nociceptive and proprioceptive fibers. A non-cell-autonomous role of PTPRO was suggested previously in RGC axon guidance, because the PTPRO ectodomain is chemorepulsive for RGC axons ex vivo (Stepanek et al., 2001). Conditional ablation of PTPRO in sensory axons versus their target fields should resolve these mechanistic questions.

In summary, our results have shown that PTPRO fine tunes growth factor signaling in a cell-type-specific manner and thereby controls the axonal branch morphology of developing TG neurons. Future work will show whether this function of PTPRO also controls the connectivity of TG neurons in the adult. It will also be interesting to explore whether PTPRO activity is regulated by interaction with extracellular ligands. Our work has also shown that the regulation of Eph receptor-mediated developmental processes by RPTPs has evolved differently between chick and mouse. It will be important to identify the molecular features that determine substrate specificity of CPTPRO and $\mathrm{mPTPRO}$ and possibly of other protein tyrosine phosphatases.

\section{References}

Airaksinen MS, Saarma M (2002) The GDNF family: signalling, biological functions and therapeutic value. Nat Rev Neurosci 3:383-394. CrossRef Medline

Beltran PJ, Bixby JL, Masters BA (2003) Expression of PTPRO during mouse development suggests involvement in axonogenesis and differentiation of NT-3 and NGF-dependent neurons. J Comp Neurol 456:384395. CrossRef Medline

Bentley CA, Lee KF (2000) p75 is important for axon growth and schwann cell migration during development. J Neurosci 20:7706-7715. Medline

Ben-Zvi A, Ben-Gigi L, Klein H, Behar O (2007) Modulation of semaphorin3A activity by p75 neurotrophin receptor influences peripheral axon patterning. J Neurosci 27:13000-13011. CrossRef Medline

Bonanomi D, Pfaff SL (2010) Motor axon pathfinding. Cold Spring Harb Perspect Biol 2:a001735. CrossRef Medline

Davies AM (1989) Intrinsic differences in the growth rate of early nerve fibres related to target distance. Nature 337:553-555. CrossRef Medline

Davies AM (1997) Studies of neurotrophin biology in the developing trigeminal system. J Anat 191:483-491. CrossRef Medline

Dechant G (2001) Molecular interactions between neurotrophin receptors. Cell Tissue Res 305:229-238. CrossRef Medline

Dudanova I, Kao TJ, Herrmann JE, Zheng B, Kania A, Klein R (2012) Genetic evidence for a contribution of EphA:ephrinA reverse signaling to motor axon guidance. J Neurosci 32:5209-5215. CrossRef Medline

Eberhart J, Swartz ME, Koblar SA, Pasquale EB, Krull CE (2002) EphA4 constitutes a population-specific guidance cue for motor neurons. Dev Biol 247:89-101. CrossRef Medline

Encinas M, Rozen EJ, Dolcet X, Jain S, Comella JX, Milbrandt J, Johnson EM Jr (2008) Analysis of Ret knockin mice reveals a critical role for IKKs, but not PI 3-K, in neurotrophic factor-induced survival of sympathetic neurons. Cell Death Differ 15:1510-1521. CrossRef Medline

Erzurumlu RS, Murakami Y, Rijli FM (2010) Mapping the face in the somatosensory brainstem. Nat Rev Neurosci 11:252-263. CrossRef Medline

Erzurumlu RS, Chen ZF, Jacquin MF (2006) Molecular determinants of the face map development in the trigeminal brainstem. Anat Rec A Discov Mol Cell Evol Biol 288:121-134. CrossRef Medline

Faux C, Hawadle M, Nixon J, Wallace A, Lee S, Murray S, Stoker A (2007) PTPsigma binds and dephosphorylates neurotrophin receptors and can suppress NGF-dependent neurite outgrowth from sensory neurons. Biochim Biophys Acta 1773:1689-1700. CrossRef Medline

Gonzalez-Brito MR, Bixby JL (2009) Protein tyrosine phosphatase receptor type $\mathrm{O}$ regulates development and function of the sensory nervous system. Mol Cell Neurosci 42:458-465. CrossRef Medline

Gutierrez H, Davies AM (2007) A fast and accurate procedure for deriving the Sholl profile in quantitative studies of neuronal morphology. J Neurosci Methods 163:24-30. CrossRef Medline

Helmbacher F, Schneider-Maunoury S, Topilko P, Tiret L, Charnay P (2000) Targeting of the EphA4 tyrosine kinase receptor affects dorsal/ventral pathfinding of limb motor axons. Development 127:3313-3324. Medline

Hou L, Wang J, Zhou Y, Li J, Zang Y (2011) Structural insights into the homology and differences between mouse protein tyrosine phosphatasesigma and human protein tyrosine phosphatase-sigma. Acta Biochim Biophys Sin (Shanghai) 43:977-988. CrossRef Medline

Hower AE, Beltran PJ, Bixby JL (2009) Dimerization of tyrosine phosphatase PTPRO decreases its activity and ability to inactivate TrkC. J Neurochem 110:1635-1647. CrossRef Medline

Huang EJ, Zang K, Schmidt A, Saulys A, Xiang M, Reichardt LF (1999a) POU domain factor Brn-3a controls the differentiation and survival of trigeminal neurons by regulating Trk receptor expression. Development 126:2869-2882. Medline

Huang EJ, Wilkinson GA, Fariñas I, Backus C, Zang K, Wong SL, Reichardt LF (1999b) Expression of Trk receptors in the developing mouse trigeminal ganglion: in vivo evidence for NT-3 activation of TrkA and TrkB in addition to TrkC. Development 126:2191-2203. Medline

Kotani T, Murata Y, Ohnishi H, Mori M, Kusakari S, Saito Y, Okazawa H, Bixby JL, Matozaki T (2010) Expression of PTPRO in the interneurons of adult mouse olfactory bulb. J Comp Neurol 518:119-136. CrossRef Medline

Kramer ER, Knott L, Su F, Dessaud E, Krull CE, Helmbacher F, Klein R (2006) Cooperation between GDNF/Ret and ephrinA/EphA4 signals for motor-axon pathway selection in the limb. Neuron 50:35-47. CrossRef Medline

Ledda F, Bieraugel O, Fard SS, Vilar M, Paratcha G (2008) Lrig1 is an endogenous inhibitor of Ret receptor tyrosine kinase activation, downstream signaling, and biological responses to GDNF. J Neurosci 28:39-49. CrossRef Medline

Luo W, Wickramasinghe SR, Savitt JM, Griffin JW, Dawson TM, Ginty DD 
(2007) A hierarchical NGF signaling cascade controls Ret-dependent and Ret-independent events during development of nonpeptidergic DRG neurons. Neuron 54:739-754. CrossRef Medline

Luo W, Enomoto H, Rice FL, Milbrandt J, Ginty DD (2009) Molecular identification of rapidly adapting mechanoreceptors and their developmental dependence on ret signaling. Neuron 64:841-856. CrossRef Medline

Luukko K, Løes S, Kvinnsland IH, Kettunen P (2005) Expression of ephrin-A ligands and EphA receptors in the developing mouse tooth and its supporting tissues. Cell Tissue Res 319:143-152. CrossRef Medline

Ma L, Tessier-Lavigne M (2007) Dual branch-promoting and branchrepelling actions of Slit/Robo signaling on peripheral and central branches of developing sensory axons. J Neurosci 27:6843-6851. CrossRef Medline

Mandai K, Guo T, St Hillaire C, Meabon JS, Kanning KC, Bothwell M, Ginty DD (2009) LIG family receptor tyrosine kinase-associated proteins modulate growth factor signals during neural development. Neuron 63: 614-627. CrossRef Medline

Markus A, Zhong J, Snider WD (2002) Raf and akt mediate distinct aspects of sensory axon growth. Neuron 35:65-76. CrossRef Medline

Marmigère F, Ernfors P (2007) Specification and connectivity of neuronal subtypes in the sensory lineage. Nat Rev Neurosci 8:114-127. CrossRef Medline

Matozaki T, Murata Y, Mori M, Kotani T, Okazawa H, Ohnishi H (2010) Expression, localization, and biological function of the R3 subtype of receptor-type protein tyrosine phosphatases in mammals. Cell Signal 22: 1811-1817. CrossRef Medline

Nievergall E, Janes PW, Stegmayer C, Vail ME, Haj FG, Teng SW, Neel BG, Bastiaens PI, Lackmann M (2010) PTP1B regulates Eph receptor function and trafficking. J Cell Biol 191:1189-1203. CrossRef Medline

North HA, Karim A, Jacquin MF, Donoghue MJ (2010) EphA4 is necessary for spatially selective peripheral somatosensory topography. Dev Dyn 239:630-638. CrossRef Medline

Rashid T, Upton AL, Blentic A, Ciossek T, Knöll B, Thompson ID, Drescher U (2005) Opposing gradients of ephrin-As and EphA7 in the superior colliculus are essential for topographic mapping in the mammalian visual system. Neuron 47:57-69. CrossRef Medline

Reichardt LF (2006) Neurotrophin-regulated signalling pathways. Philos Trans R Soc Lond B Biol Sci 361:1545-1564. CrossRef Medline
Rochlin MW, O'Connor R, Giger RJ, Verhaagen J, Farbman AI (2000) Comparison of neurotrophin and repellent sensitivities of early embryonic geniculate and trigeminal axons. J Comp Neurol 422:579-593. CrossRef Medline

Shintani T, Noda M (2008) Protein tyrosine phosphatase receptor type Z dephosphorylates TrkA receptors and attenuates NGF-dependent neurite outgrowth of PC12 cells. J Biochem 144:259-266. CrossRef Medline

Shintani T, Ihara M, Sakuta H, Takahashi H, Watakabe I, Noda M (2006) Eph receptors are negatively controlled by protein tyrosine phosphatase receptor type O. Nat Neurosci 9:761-769. CrossRef Medline

Siu R, Fladd C, Rotin D (2007) N-cadherin is an in vivo substrate for protein tyrosine phosphatase sigma (PTPsigma) and participates in PTPsigmamediated inhibition of axon growth. Mol Cell Biol 27:208-219. CrossRef Medline

Stepanek L, Sun QL, Wang J, Wang C, Bixby JL (2001) CRYP-2/cPTPRO is a neurite inhibitory repulsive guidance cue for retinal neurons in vitro. J Cell Biol 154:867-878. CrossRef Medline

Stepanek L, Stoker AW, Stoeckli E, Bixby JL (2005) Receptor tyrosine phosphatases guide vertebrate motor axons during development. J Neurosci 25:3813-3823. CrossRef Medline

Wang F, Wolfson SN, Gharib A, Sagasti A (2012) LAR receptor tyrosine phosphatases and HSPGs guide peripheral sensory axons to the skin. Curr Biol 22:373-382. CrossRef Medline

Wharram BL, Goyal M, Gillespie PJ, Wiggins JE, Kershaw DB, Holzman LB, Dysko RC, Saunders TL, Samuelson LC, Wiggins RC (2000) Altered podocyte structure in GLEPP1 (Ptpro)-deficient mice associated with hypertension and low glomerular filtration rate. J Clin Invest 106:1281-1290. CrossRef Medline

Wichterle H, Lieberam I, Porter JA, Jessell TM (2002) Directed differentiation of embryonic stem cells into motor neurons. Cell 110:385-397. CrossRef Medline

Yang T, Massa SM, Longo FM (2006) LAR protein tyrosine phosphatase receptor associates with TrkB and modulates neurotrophic signaling pathways. J Neurobiol 66:1420-1436. CrossRef Medline

Zhong J, Li X, McNamee C, Chen AP, Baccarini M, Snider WD (2007) Raf kinase signaling functions in sensory neuron differentiation and axon growth in vivo. Nat Neurosci 10:598-607. CrossRef Medline 